\title{
Antitumor activity of 2-[(2E)-3,7-dimethyl-2,6-octadienyl]-6- methyl-2,5-cyclohexadiene-1,4-dione isolated from the aerial part of Atractylodes macrocephala in hepatocellular carcinoma
}

\author{
LEI LI ${ }^{1}$, RUI ZHAO ${ }^{2}$, YING LI $^{3}$ and WEN-HUI WANG ${ }^{1}$ \\ ${ }^{1}$ Interventional Radiology Department, The First Hospital of Lanzhou University, Lanzhou, Gansu 730000; \\ ${ }^{2}$ Liver Disease Department, The Second Hospital of Lanzhou University, Lanzhou, Gansu 730030; \\ ${ }^{3}$ Liver Transplantation Center, The First Hospital of Lanzhou University, Lanzhou, Gansu 730000, P.R. China
}

Received June 14, 2016; Accepted June 19, 2017

DOI: $10.3892 / \mathrm{mmr} .2017 .7385$

\begin{abstract}
E)-3,7-dimethyl-2,6-octadienyl]-6-methy 1-2,5-cyclohexadiene-1,4-dione (DMD) is a compound isolated from Atractylodes macrocephala; however, its antitumor activity has not yet been investigated. Therefore, the present study aimed to investigate the antitumor activity of DMD in the H22 mouse hepatocellular carcinoma (HCC) cell line in vitro and in vivo. In the present study, the antiproliferative effects of DMD against $\mathrm{H} 22$ cells were evaluated using the MTT assay in vitro. Furthermore, xenograft nude mice were established to evaluate the antitumor effects of DMD on $\mathrm{H} 22$ cells in vivo. In addition, apoptosis of $\mathrm{H} 22$ cells was determined by flow cytometry with Annexin V-fluorescein isothiocyanate/propidium iodide staining, and western blotting was subsequently performed to examine the expression levels of proteins associated with apoptosis, and c-Jun $\mathrm{N}$-terminal kinase (JNK), p38 and extracellular signal-regulated kinase (ERK)1/2 mitogen-activated protein kinases (MAPKs). The results demonstrated that DMD exerts an antitumor effect against $\mathrm{H} 22$ cells in vitro and in vivo, and the underlying mechanism may be associated with mitochondria-mediated apoptosis through upregulation of cytochrome $c$, cleaved (c)-caspase-3, c-caspase-9, c-caspase-7 and B-cell lymphoma 2 (Bcl-2)-associated X protein, and downregulation of Bcl-2. In addition, the antitumor effects of DMD against $\mathrm{H} 22$ cells may be also associated with the MAPK signaling pathway via increased p-JNK and reduced p-ERK1/2 expression. In conclusion, the present study demonstrated the DMD exerts
\end{abstract}

Correspondence to: Professor Wen-Hui Wang, Interventional Radiology Department, The First Hospital of Lanzhou University, 1 Donggang West Road, Lanzhou, Gansu 730000, P.R. China E-mail: wangwenhuilz@163.com

Key words: 2-[(2E)-3,7-dimethyl-2,6-octadienyl]-6-methyl-2,5cyclohexadiene-1,4-dione, hepatocellular carcinoma, H22 cell line, mitochondria-mediated apoptosis, mitogen-activated protein kinase pathway antitumor effects against $\mathrm{HCC}$ in mice and provides a scientific basis for the clinical use of DMD for the treatment of HCC.

\section{Introduction}

Hepatocellular carcinoma (HCC) is one of the most common forms of liver cancer and is one of the major causes of mortality among patients with chronic liver disease worldwide $(1,2)$. It has been reported that the mean survival rate of HCC is $<5 \%$ and $\mathrm{HCC}$ is the third most common cause of cancer-associated mortality worldwide $(3,4)$. In addition, HCC is one of the most common and malignant cancers, with an increasing incidence rate, particularly in Europe and East Asia (5). At present, chemotherapy with synthetic drugs is commonly used to treat $\mathrm{HCC}$; however, serious side effects are associated with this treatment (6). HCC also exhibits a poor response to treatment modalities and resistance to systemic chemotherapy (7). Therefore, there is an urgent requirement to develop novel anti-HCC agents with improved therapeutic effects.

Traditional Chinese medicine (TCM) has been used for centuries, and it has been reported that plant-derived medicines are safer than synthetic drugs (8). In addition, TCM has been reported to be effective in the treatment of various diseases, particularly those that cannot be treated by modern synthetic drugs (9). The rhizome of Atractylodes macrocephala, a recognized herbal medicine in China, has been commonly used to treat conditions including edema, spleen-deficiency, diarrhea and abdominal distention (10). Various other effects of the rhizome of A. macrocephala have also been described, including antibacterial, anti-aging and antitumor effects (10). It has previously been reported that 2-[(2E)-3,7dimethyl-2,6-octadienyl]-6-methyl-2,5-cyclohexadiene-1,4dione (DMD), the structure of which is presented in Fig. 1, is a compound isolated from the aerial part of A. macrocephala (APM), however, its antitumor activities have not yet been investigated (11).

The present study obtained a quantity of DMD from the APM and investigated its antitumor effects against $\mathrm{H} 22$ cells in vitro and in vivo, and explored the potential underlying pharmacological mechanism to provide a scientific basis for the clinical use of DMD in the future. 


\section{Materials and methods}

Chemicals. Dimethyl sulfoxide (DMSO) and MTT were purchased from Sigma-Aldrich (Merck KGaA, Darmstadt, Germany). RPMI-1640 medium and fetal bovine serum were purchased from Gibco (Thermo Fisher Scientific, Inc., Waltham, MA, USA). Cleaved (c)-caspase-3 (cat. no. ab32499), c-caspase-9 (cat. no. ab2324) and c-caspase-7 (cat. no. ab69540) antibodies were purchased from Abcam (Cambridge, MA, USA). Cytochrome $c$ (cat. no. ab13575), B-cell lymphoma 2 (Bcl-2)-associated X protein (Bax; cat. no. ab32503), Bcl-2 (cat. no. ab32124), c-Jun N-terminal kinase (JNK; cat. no. ab76125), phosphorylated (p)-JNK (cat. no. ab4821), extracellular signal-regulated kinase (ERK)1/2 (cat. no. ab17942), p-ERK1/2 (cat. no. ab200807), p38 (cat. no. ab31828), p-p38 (cat. no. ab47363) and GAPDH (cat. no. ab8245) antibodies were purchased from Abcam (Cambridge, MA, USA). Bicinchoninic acid (BCA) protein assay reagent was purchased from Beyotime Institute of Biotechnology (Haimen, China). Silica-gel (100-200 mesh) was purchased from Qingdao Haiyang Chemical Co., Ltd. (Qingdao, China). The Annexin V-fluorescein isothiocyanate (FITC)/propidium iodide (PI) kit was purchased from BD Biosciences (San Jose, CA, USA). All other chemicals used in this study were of analytical reagent grade.

Animals. A total 12 BALB/C nude mice (5-6 weeks old; 8-9 g), were purchased from the Shanghai Laboratory Animal Center (Shanghai, China). The animals were maintained under controlled conditions $\left(21 \pm 1^{\circ} \mathrm{C}\right.$ and $\left.30-70 \%\right)$ with a 12 -h light/dark cycle and free access to food and water. All animal treatments were strictly in accordance with international ethical guidelines and the National Institutes of Health Guide concerning the Care and Use of Laboratory Animals (12), and the experiments were performed with the approval of the Animal Experimentation Ethics Committee of The First Hospital of Lanzhou University (Lanzhou, Gansu, China).

Preparation of DMD. The APM was collected from Jiande, China in August 2014. The dried APM was powdered and extracted five times with $75 \%$ ethanol by percolation extraction for 3 days each time. The solvent was evaporated under vacuum to obtain the crude extract. Subsequently, the crude extract was suspended in water and partitioned with petroleum ether, ethyl acetate (EtOAc) and n-butanol sequentially. The EtOAc fraction was subjected to repeated column chromatography over silica gel (100-200 mesh) and eluted with petroleum ether-EtOAc (97\%:3\%, 90\%:10\%, 80\%:20\%, 70\%:30\% and 50\%:50\%). Combination of similar fractions on the basis of thin layer chromatography (TLC) analysis afforded 5 fractions (I-V). The TLC spots were visualized using a ZF-1 Ultraviolet analyzer (Shanghai King Tech Industry Co., Ltd., Shanghai, China) at $254 \mathrm{~nm}$ and $365 \mathrm{~nm}$ using the sulfuric acid-alcohol chromogenic agent. As described previously (11), DMD was isolated from fraction IV using further column chromatography over a silica gel (200-300 mesh) and eluted with petroleum ether:EtOAc (50\%:50\%).

Identification of the compound. The isolated DMD was identified by ${ }^{1} \mathrm{H}$-nuclear magnetic resonance (NMR) and ${ }^{13} \mathrm{C}-\mathrm{NMR}$.
The ${ }^{1} \mathrm{H}-\mathrm{NMR}$ and ${ }^{13} \mathrm{C}-\mathrm{NMR}$ spectrum data of this compound are as follows: Brown oil; ${ }^{1} \mathrm{H}-\mathrm{NMR}\left(\mathrm{CDCl}_{3}, 600 \mathrm{MHz}, \mathrm{J} / \mathrm{Hz}\right)$ d: $6.62(1 \mathrm{H}, \mathrm{m}, \mathrm{H}-6), 6.57(1 \mathrm{H}, \mathrm{m}, \mathrm{H}-2), 5.11(1 \mathrm{H}, \mathrm{t}, \mathrm{J}=7.3 \mathrm{~Hz}$, H-2'), 5.03 (1H, t, J=6.8 Hz, H-6'), 3.17 (2H, d, J=7.3 Hz, H2-1'), $2.18\left(2 \mathrm{H}, \mathrm{m}, \mathrm{H} 2-5^{\prime}\right), 2.13\left(5 \mathrm{H}, \mathrm{m}, \mathrm{H} 2-4{ }^{\prime}\right.$ and $\left.\mathrm{H} 3-7\right), 1.74(3 \mathrm{H}, \mathrm{s}$, $\left.\mathrm{H}^{-9}\right), 1.67$ (3H, s, H-10'), 1.64 (3H, s, H- $\left.8^{\prime}\right)$; ${ }^{13} \mathrm{C}-\mathrm{NMR}\left(\mathrm{CDCl}_{3}\right.$, $150 \mathrm{M} \mathrm{Hz}) \mathrm{d}: 189.52$ (C-1), 182.54 (C-4), 148.81 (C-2), 143.59 (C-6), 134.96 (C-3'), 132.96 (C-3), 131.12 (C-5), 130.42 (C-7'), 122.43 (C-6'), 113.56 (C-2'), 40.11 (C-4'), 28.01 (C-1'), 25.99 (C-5'), 25.01 (C-9'), 18.03 (C-8'), 16.03 (C-10'), 14.93 (C-7). According to these spectral data, physicochemical properties and a reported study (13), the compound was identified as DMD.

Cell culture and determination of cell viability. Human HL-60 myeloid leukemia, A549 lung cancer, MCF-7 breast cancer, HCT-8 colon cancer and HeLa cervical carcinoma cell lines, and the H22 mouse HCC cell line, were purchased from the American Type Culture Collection (Manassas, VA, USA). The cells were cultured in RPMI-1640 medium (Gibco; Thermo Fisher Scientific, Inc.) supplemented with $10 \%$ fetal bovine serum (Gibco; Thermo Fisher Scientific, Inc.) and antibiotics (100 U/ml penicillin and $100 \mu \mathrm{g} / \mathrm{ml}$ streptomycin). The cell lines were maintained at $37^{\circ} \mathrm{C}$ in an atmosphere containing $5 \% \mathrm{CO}_{2} / 95 \%$ air.

Cell viability was determined using the MTT assay according to the previously reported method (14). Cell suspension $\left(100 \mu 1 ; 5 \times 10^{5}\right.$ cells $\left./ \mathrm{ml}\right)$ were seeded in $96-$ well plates and cultured for $24 \mathrm{~h}$ at $37^{\circ} \mathrm{C}$. Cells were then treated with DMD at various concentrations $(10,20,40,60,80$ and $100 \mu \mathrm{g} / \mathrm{ml})$ and cultured for $24 \mathrm{~h}$ at $37^{\circ} \mathrm{C}$. The control cells were cultured without DMD treatment for $24 \mathrm{~h}$ at $37^{\circ} \mathrm{C}$. Subsequently, the MTT assay was performed to determine the percentage of cell proliferation inhibition $(n=4)$ by detecting the optical density (OD) at $570 \mathrm{~nm}$ using a microplate reader (Bio-Rad Laboratories, Inc., Hercules, CA, USA). The half maximal inhibitory concentration $\left(\mathrm{IC}_{50}\right)$ values of DMD on HL-60, A549, MCF-7, HCT-8, $\mathrm{HeLa}$ and $\mathrm{H} 22$ cells were calculated. In addition, to investigate the dose-dependent and time-dependent effects of DMD, H22 cells were treated with $\operatorname{DMD}(15,30$ and $60 \mu \mathrm{g} / \mathrm{ml})$ for 12,24 , 36 and $48 \mathrm{~h}$. The inhibitory rate was calculated according to the following formula: $\left[\left(\mathrm{OD}_{\text {control }}-\mathrm{OD}_{\text {treatmen }}\right) / \mathrm{OD}_{\text {control }}\right]$ x 100 .

Xenograft model in mice. To evaluate the antitumor effects of DMD against $\mathrm{H} 22$ cells in vivo, mice were divided into two groups ( $\mathrm{n}=6 /$ group$)$, including control and DMD $(40 \mathrm{mg} / \mathrm{kg})$ groups. Nude mice were subcutaneously injected in the back on the right-hand side with $\mathrm{H} 22$ cells $\left(0.2 \mathrm{ml} ; 1 \times 10^{7}\right.$ cells per mouse). Once the tumors had grown to $2-3 \mathrm{~mm}$ in diameter, mice were treated intraperitoneally with DMD ( $40 \mathrm{mg} / \mathrm{kg} / \mathrm{day})$ for 20 days and an equal volume of solvent control $(0.5 \%$ DMSO). Mice were observed over 20 days, and tumor sizes were measured every 5 days after the tumor inoculation. Tumor diameters were determined using a vernier caliper, and the tumor volumes were calculated according to the following formula (9): Volume $=\left(\right.$ width $^{2} \mathrm{x}$ length $) / 2$.

Apoptosis assay. Apoptotic cells were detected by flow cytometry on a FACSCalibur cytometer (BD Biosciences). Firstly, $2 \mathrm{ml} \mathrm{H} 22$ cells $\left(5 \times 10^{5} / \mathrm{ml}\right)$ were seeded in 6 -well 


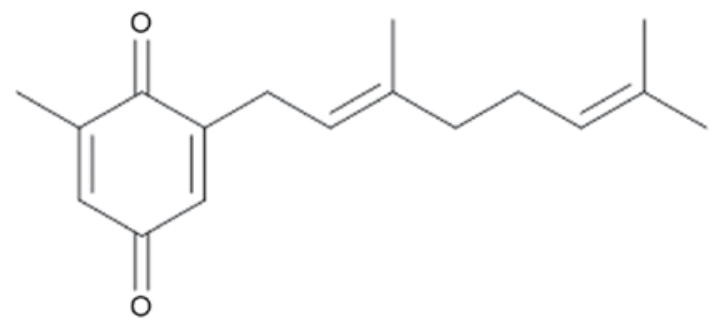

Figure 1. Chemical structure of 2-[(2E)-3,7-dimethyl-2,6-octadienyl]6-methyl-2,5-cyclohexadiene-1,4-dione.

plates for $24 \mathrm{~h}$ at $37^{\circ} \mathrm{C}$. On the following day, the cells were treated with 15,30 and $60 \mu \mathrm{g} / \mathrm{ml}$ DMD. After $48 \mathrm{~h}$, cells were trypsinized, washed with PBS and stained using the Annexin V-FITC/PI kit (200 $\mu \mathrm{l}$ Annexin V-FITC and $10 \mu \mathrm{l}$ PI for every $1 \times 10^{5}$ cells), according to the manufacturer's protocol.

Western blotting. Cells were treated with DMD (15, 30 and $60 \mu \mathrm{g} / \mathrm{ml})$ for $24 \mathrm{~h}$ at $37^{\circ} \mathrm{C}$. Cells $\left(5 \times 10^{6}\right)$ were then harvested and homogenized with lysis buffer for $10 \mathrm{~min}$ and centrifuged at $4^{\circ} \mathrm{C}$ for $5 \mathrm{~min}(10,000 \mathrm{x} \mathrm{g})$. Total protein was extracted from cells using the cell lysis buffer for western blotting and IP (Beyotime Institute of Biotechnology; cat. no. P0013), and the protein concentration was determined using the BCA protein assay reagent (Beyotime Institute of Biotechnology; cat. no. P0012S). Subsequently, $35 \mu$ g protein was separated by $12 \%$ SDS-PAGE and blotted onto polyvinylidene fluoride membranes. Membranes were blocked with $5 \%$ fat-free dry milk in $1 \mathrm{X}$ TBST (containing $0.1 \%$ Tween-20; Beyotime Institute of Biotechnology; cat. no. P0233) at room temperature for $2 \mathrm{~h}$. Then, membranes were incubated with the following primary antibodies: Cytochrome $\mathrm{c}$ (dilution 1:1,000), c-caspase-3 (dilution 1:1,000), c-caspase-9 (dilution 1:1,000), c-caspase-7 (dilution 1:1,000), Bax (dilution 1:1,000), Bcl-2 (dilution 1:1,000), p38 (dilution 1:1,000), p-p38 (dilution 1:1,000), JNK (dilution 1:1,000), p-JNK (dilution 1:1,000), ERK1/2 (dilution 1:1,000), p-ERK1/2 (dilution 1:1,000) and GAPDH (dilution 1:2,000) at $4^{\circ} \mathrm{C}$ overnight. Followed by incubation with horseradish peroxidase-conjugated secondary antibodies (1:2,000; Beyotime Institute of Biotechnology; cat. no. A0286) at room temperature for $1 \mathrm{~h}$. Proteins bands were visualized using Beyo Electrochemiluminescence Star reagents (Beyotime Institute of Biotechnology; cat. no. P0018A). Immunoblotting signals were evaluated quantitatively using the ImageQuant ${ }^{\mathrm{TM}}$ LAS 4000 digital imaging system (GE Healthcare Bio-Sciences, Pittsburgh, PA, USA). To normalize for protein loading, antibodies directed against GAPDH were used, and protein expression was expressed relative to GAPDH.

Statistical analysis. Data are presented as the mean \pm standard deviation and the significance of differences between groups was determined by one-way analysis of variance followed by a Dunnett's multiple comparisons post hoc test using SPSS software (SPSS for Windows v19.0; IBM Corp., Armonk, NY, USA). $\mathrm{P}<0.05$ was considered to indicate a statistically significant difference.

\section{Results}

$I_{50}$ values of DMD on HL-60, A549, MCF-7, HCT-8, HeLa and $H 22$ cell lines. The antiproliferative effects of DMD on HL-60, A549, MCF-7, HCT-8, HeLa and H22 cell lines were investigated, and the results are presented in Table I. The results demonstrated that DMD exhibited an antiproliferative effect against the $\mathrm{H} 22$ cell line, and the $\mathrm{IC}_{50}$ value was $44.29 \pm 3.97 \mu \mathrm{g} / \mathrm{ml}$, which is $<50 \mu \mathrm{g} / \mathrm{ml}$. Furthermore, DMD displayed moderate antiproliferative activities against HL-60 and A549 cell lines ( IC $_{50}$ values were $87.43 \pm 3.12 \mu \mathrm{g} / \mathrm{ml}$ and $68.19 \pm 1.08 \mu \mathrm{g} / \mathrm{ml}$, respectively). However, no obvious antitumor effects were observed against MCF-7, HCT-8 and HeLa cell lines $\left(\mathrm{IC}_{50}>100 \mu \mathrm{g} / \mathrm{ml}\right)$.

Inhibitory effects of DMD against H22 cells in vitro and in vivo. The antitumor activity of DMD against $\mathrm{H} 22$ cells in vivo and in vitro was evaluated in the present study. The results demonstrated that DMD possesses significant cytotoxicity against $\mathrm{H} 22$ cells, as cell viability was significantly reduced, compared with control cells following treatment with $15 \mu \mathrm{g} / \mathrm{ml}(\mathrm{P}<0.05), 30 \mu \mathrm{g} / \mathrm{ml}(\mathrm{P}<0.01)$ and $60 \mu \mathrm{g} / \mathrm{ml}(\mathrm{P}<0.01)$ $\mathrm{DMD}$, and viability was reduced in a concentration-dependent manner (Fig. 2A). In addition, DMD (15, 30 and $60 \mu \mathrm{g} / \mathrm{ml})$ also exhibited time-dependent cytotoxic effects against $\mathrm{H} 22$ cells (Fig. 2B). Furthermore, the antitumor activity of DMD against $\mathrm{H} 22$ cells in vivo was further evaluated in a mouse xenograft model. As demonstrated in Fig. 2C, DMD (40 mg/kg) significantly inhibited tumor growth, compared with the control group $(\mathrm{P}<0.01)$.

Proapoptotic effects of DMD on H22 cells. The aforementioned results demonstrated that DMD exhibits notable antitumor activity against $\mathrm{H} 22 \mathrm{HCC}$ cells. To determine whether the antitumor activity of DMD resulted from induction of apoptosis, apoptotic H22 cells were detected by staining with Annexin V-FITC/PI followed by flow cytometry. As presented in Fig. 3, the percentage of apoptotic cells increased gradually when treated with increasing concentrations of DMD $(15,30$ and $60 \mu \mathrm{g} / \mathrm{ml}$ ), and the percentage was significantly increased, compared with control cells at all doses $(\mathrm{P}<0.01)$. These results indicated that DMD may induce $\mathrm{H} 22$ cell death by inducing apoptosis.

Exposure of $\mathrm{H} 22$ cells to DMD results in upregulation of cytochrome c, c-caspase-3, c-caspase-9, c-caspase-7 and $\mathrm{Bax}$, and downregulation of $\mathrm{Bcl}-2$. To investigate the potential mechanism by which DMD induces apoptosis of H22 cells, the protein expression levels of cytochrome $c$, c-caspase-3, c-caspase-9, c-caspase-7, Bax and Bcl-2 in H22 cells were detected. As demonstrated in Figs. 4-6, the expression levels of cytochrome $c(\mathrm{P}<0.01)$, c-caspase-3 $(\mathrm{P}<0.01)$, c-caspase-9 $(\mathrm{P}<0.01)$ and $\operatorname{Bax}(\mathrm{P}<0.01)$ were significantly upregulated following treatment with $\operatorname{DMD}(15,30$ and $60 \mu \mathrm{g} / \mathrm{ml})$ in a concentration-dependent manner. In addition, c-caspase-7 expression was upregulated in response to DMD, in a concentration-dependent manner. C-caspase-7 was significantly upregulated following treatment with $30 \mu \mathrm{g} / \mathrm{ml}(\mathrm{P}<0.05)$ and $60 \mu \mathrm{g} / \mathrm{ml} \mathrm{DMD}(\mathrm{P}<0.01)$, compared with the control group; however, no significant difference was observed in c-caspase-7 
Table I. $\mathrm{IC}_{50}$ values of DMD on various cancer cell lines.

\begin{tabular}{lc}
\hline Cell line & $\mathrm{IC}_{50}(\mu \mathrm{g} / \mathrm{ml})$ \\
\hline HL-60 & $87.43 \pm 3.12$ \\
A549 & $68.19 \pm 1.08$ \\
MCF-7 & $>100$ \\
HCT-8 & $>100$ \\
HeLa & $>100$ \\
H22 & $44.29 \pm 3.97$
\end{tabular}

Cells were treated with DMD for $24 \mathrm{~h}$ and cell viability was determined by MTT assay. Data are presented as the mean \pm standarddeviation.DMD,2-[(2E)-3,7-dimethyl-2,6-octadienyl]-6methyl-2,5-cyclohexadiene-1,4-dione; $\mathrm{IC}_{50}$, half maximal inhibitory concentration.

expression following treatment with $15 \mu \mathrm{g} / \mathrm{ml}$ DMD (Fig. 5). However, as demonstrated in Fig. 6, DMD significantly reduced the expression of $\mathrm{Bcl}-2$ in a concentration-dependent manner, compared with the control group $(\mathrm{P}<0.01)$. These results indicated that DMD-induced apoptosis of $\mathrm{H} 22$ cells may be associated with the mitochondria-mediated apoptotic pathway.

Effects of DMD on p38, p-p38,JNK, p-JNK, ERK1/2 and $p-E R K 1 / 2$ protein expression. To investigate other potential mechanisms of DMD action on H22 cells, the expression levels of proteins in the mitogen-activated protein kinase (MAPK) pathway were examined, including p38, JNK, ERK1/2, p-p38, p-JNK and p-ERK1/2. As presented in Fig. 7, the effects of DMD on p38, p-p38, JNK and ERK1/2 were not significant $(\mathrm{P}>0.05)$. However, DMD $(15,30$ and $60 \mu \mathrm{g} / \mathrm{ml})$ significantly upregulated the expression levels of $\mathrm{p}-\mathrm{JNK}(\mathrm{P}<0.01)$ and reduced the expression of p-ERK1/2 $(\mathrm{P}<0.01)$ dose-dependently, compared with the control group. Therefore, DMD-mediated apoptosis of H22 cells may also be associated with the MAPK apoptotic pathway.

\section{Discussion}

The present study systematically investigated the antitumor activity and mechanism underlying the effects of DMD isolated from the aerial part of APM on a HCC cell line in vivo and in vitro. The results indicated that DMD exhibited an antitumor effect against the $\mathrm{H} 22 \mathrm{HCC}$ cell line in vivo and in vitro, which may be associated with mitochondria-mediated intrinsic apoptosis and the MAPK pathway.

It has previously been reported that uncontrolled cell proliferation and insufficient apoptosis may be regarded as the leading causes behind the development of cancer (15). Apoptosis, which is a form of programmed cell death, is a physiological cell suicide process that is regulated by several proteins (16). In addition, it is considered to be an ideal target for cancer therapy (17). Mitochondria-mediated apoptosis is considered to be a major apoptotic pathway, and this pathway relies on the $\mathrm{Bcl}-2$ family proteins to control the
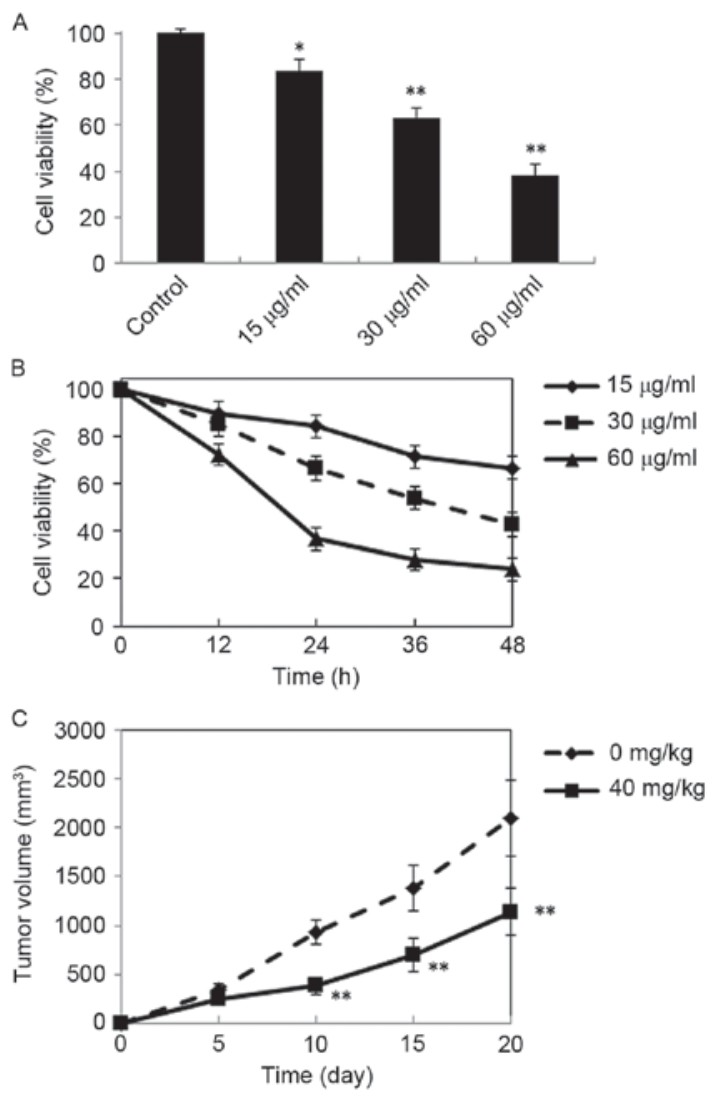

Figure 2. Antitumor effects of DMD against $\mathrm{H} 22$ cells in vitro and in vivo. (A) Inhibitory effects of DMD on the proliferation of $\mathrm{H} 22$ cells. Cells were treated with DMD at three concentrations $(15,30$ and $60 \mu \mathrm{g} / \mathrm{ml})$ for $24 \mathrm{~h}$ and cell viability was determined by MTT assay. (B) Cells were treated with DMD $(15,30$ and $60 \mu \mathrm{g} / \mathrm{ml})$ for $12,24,36$ and $48 \mathrm{~h}$, and cell viability was determined by MTT assay. (C) Tumor growth curves of xenograft mice injected with $\mathrm{H} 22$ cells and treated with DMD ( $40 \mathrm{mg} / \mathrm{kg} /$ day, i.p.) for 20 days or solvent control. Data are presented as the mean \pm standard deviation $(n=4)$. ${ }^{*} \mathrm{P}<0.05$ and ${ }^{* *} \mathrm{P}<0.01$ vs. the control group. DMD, $2-[(2 E)-3,7$-dimethyl2,6-octadienyl]-6-methyl-2,5-cyclohexadiene-1,4-dione.

release of cytochrome $c$ and activate the caspase family of proteins (18). Cytochrome $c$ is a small soluble heme-protein, which is present in the mitochondrial intermembrane space under homeostatic conditions (19). It is involved in the electron transport chain and carries electrons from the cytochrome $b c_{1}$ complex to cytochrome $c$ oxidase (20). In addition, it is established that cytochrome $c$ is the first protein released from the mitochondria of apoptotic cells, and promotes the activation of caspase- 9 (21). The caspase family consists of $\geq 14$ members, including caspase- $2,-3,-6$, $-7,-8,-9$ and -10 (22). Caspases are well known for their roles in apoptosis and inflammatory responses (23). Caspase-9 is considered to be the initiator caspase in the caspase cascade reaction and the presence of cytochrome $c$ in the cytoplasm causes the activation of caspase-9 (24). Upon activation of caspase-9, caspase-3, which is an important death protease, becomes activated; the activation of caspase- 3 may be used as a biomarker to identify cells that are undergoing apoptosis (14).

Bcl-2 family proteins have important roles in mitochondria-mediated apoptosis, and are considered to be the initial regulatory step in the induction of mitochondrial apoptosis (17). Bcl-2 and Bax are recognized as apoptosis-associated proteins. 

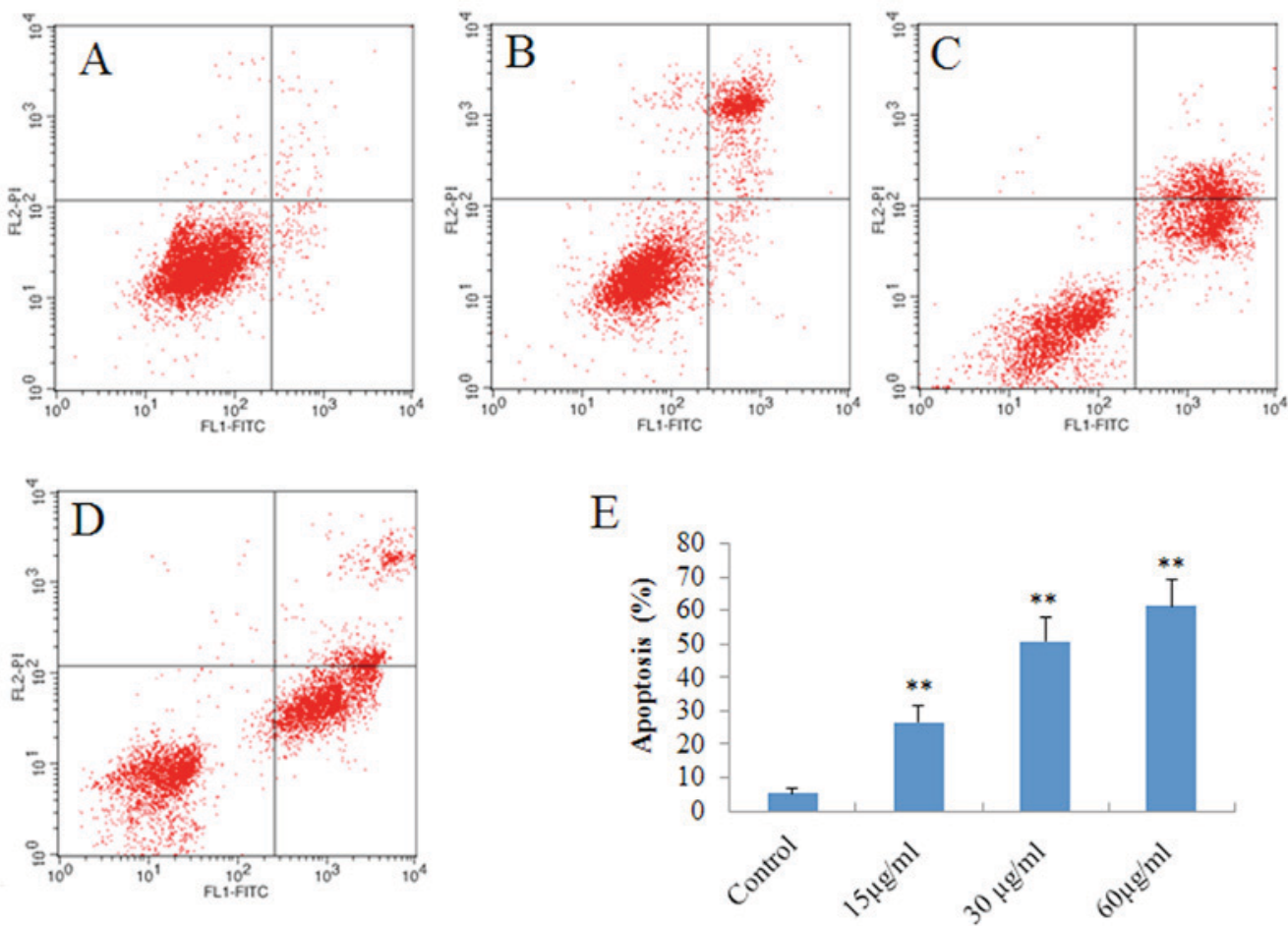

Figure 3. Apoptotic effects of DMD on H22 cells, as determined by flow cytometry. $\mathrm{H} 22$ cells were treated with DMD at 15,30 and $60 \mu \mathrm{g} / \mathrm{ml}$ for $48 \mathrm{~h}$, and apoptotic cells were detected by flow cytometry. Flow cytometry scatter plots for H22 cells treated with (A) control (B) $15 \mu \mathrm{g} / \mathrm{ml} \mathrm{DMD}$, (C) $30 \mu \mathrm{g} / \mathrm{ml} \mathrm{DMD}$ and (D) $60 \mu \mathrm{g} / \mathrm{ml}$ DMD. (E) Percentage of apoptotic cells detected in each group. Data are presented as the mean \pm standard deviation ( $\mathrm{n}=3$ ). ${ }^{* *} \mathrm{P}<0.01 \mathrm{vs}$. the control group. DMD, 2-[(2E)-3,7-dimethyl-2,6-octadienyl]-6-methyl-2,5-cyclohexadiene-1,4-dione; FITC, fluorescein isothiocyanate; PI, propidium iodide.
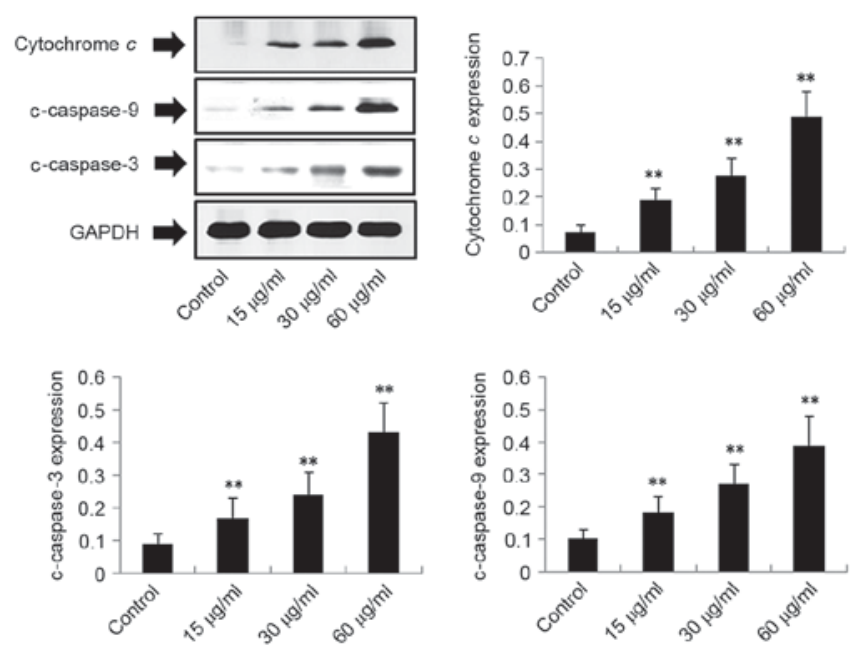

Figure 4. Effects of DMD on the protein expression levels of cytochrome $c$, c-caspase-3 and c-caspase-9. Total protein was extracted and detected by western blot analysis using antibodies against cytochrome $c, \mathrm{c}$-caspase- 3 and c-caspase-9; GAPDH was used as an internal control. Data are presented as the mean \pm standard deviation $(n=4)$. ${ }^{* *} \mathrm{P}<0.01$ vs. the control group. c-caspase, cleaved-caspase; DMD, 2-[(2E)-3,7-dimethyl-2,6-octadienyl]6-methyl-2,5-cyclohexadiene-1,4-dione.

Bcl-2 directly binds and suppresses the proapoptotic proteins of the Bcl-2 family; however, Bax directly causes cytochrome $c$ to be released into the cytoplasm or inhibits antiapoptotic Bcl-2 proteins (18). To explore the potential mechanism underlying DMD-induced apoptosis of the $\mathrm{H} 22$ cell line, the present study determined the expression of various proteins associated with the mitochondria-mediated apoptotic pathway, including
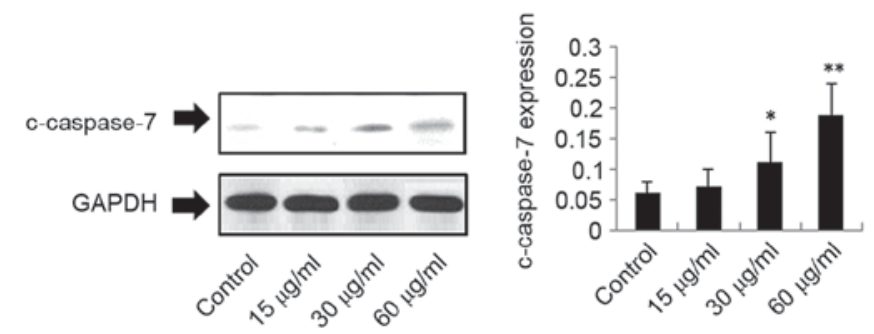

Figure 5. Effects of DMD on the protein expression levels of c-caspase-7. Total protein was extracted and detected by western blot analysis using antibodies against c-caspase-7; GAPDH was used as an internal control. Data are presented as the mean \pm standard deviation $(\mathrm{n}=4)$. ${ }^{*} \mathrm{P}<0.05$ and ${ }^{* *} \mathrm{P}<0.01$ vs. the control group. c-caspase, cleaved-caspase; DMD, 2-[(2E)-3,7-dimethyl2,6-octadienyl]-6-methyl-2,5-cyclohexadiene-1,4-dione.

cytochrome $c$, c-caspase-3, c-caspase-9, c-caspase-7, Bax and $\mathrm{Bcl}-2$. The results indicated that DMD upregulated the expression of cytochrome $c$, c-caspase-3, c-caspase-9, c-caspase-7 and Bax, and downregulated the expression of Bcl-2, compared with control cells. Therefore, the results of the present study indicated that DMD may induce mitochondria-mediated apoptosis in the $\mathrm{H} 22$ mouse HCC cell line.

MAPKs are serine/threonine kinases that function in the regulation of a wide range of cellular processes, including proliferation, differentiation and apoptosis (9). MAPKs consist of three families: JNK, ERK and p38 MAPK $(25,26)$. ERK is involved in functions that include cell proliferation and the prevention of apoptosis, and exhibits a cytoprotective role in the MAPK apoptosis pathway (27). Conversely, the JNK and p38 MAPK cascades are associated with proapoptotic effects (28). 

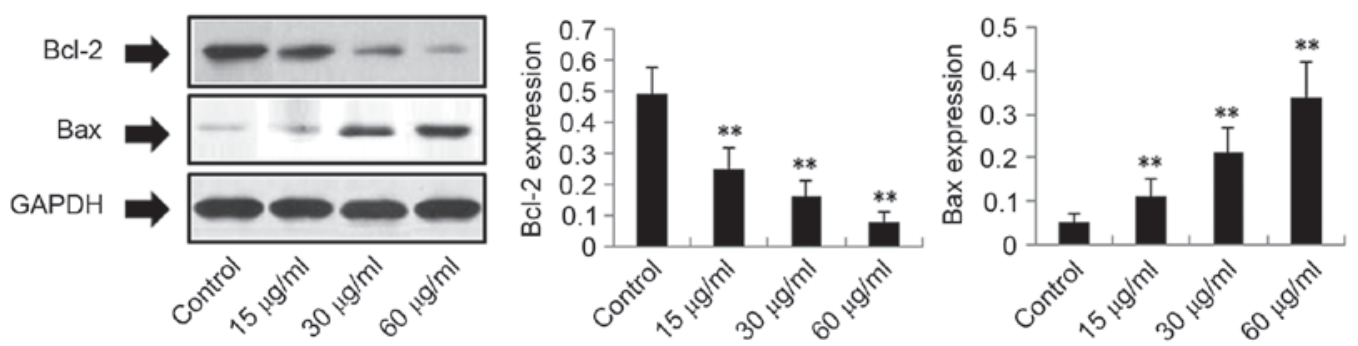

Figure 6. Effects of DMD on the protein expression levels of Bax and Bcl-2. Total protein was extracted and detected by western blot analysis using antibodies against $\mathrm{Bax}$ and $\mathrm{Bcl}-2$; GAPDH was used as an internal control. Data are presented as the mean \pm standard deviation $(\mathrm{n}=4)$. ${ }^{* *} \mathrm{P}<0.01$ vs. the control group. Bax, Bcl-2-associated X protein; Bcl-2, B-cell lymphoma 2; DMD, 2-[(2E)-3,7-dimethyl-2,6-octadienyl]-6-methyl-2,5-cyclohexadiene-1,4-dione.

A

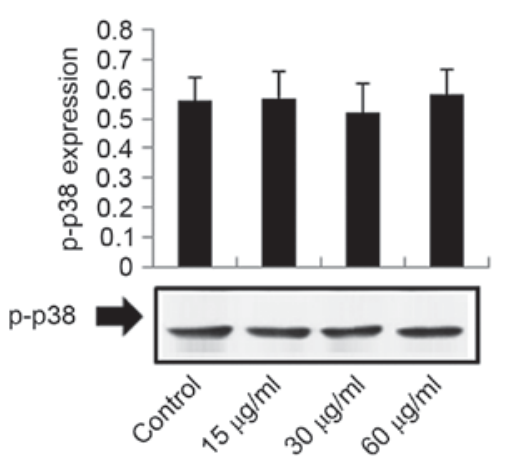

C

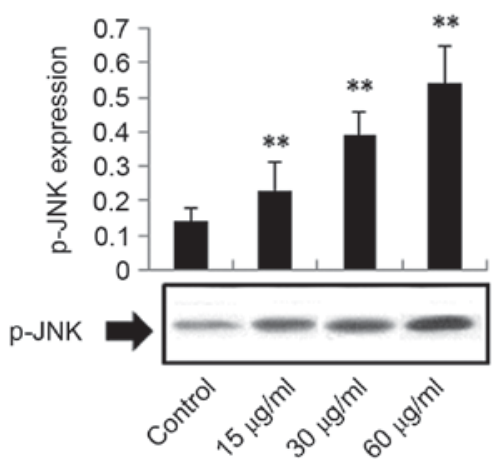

$E$

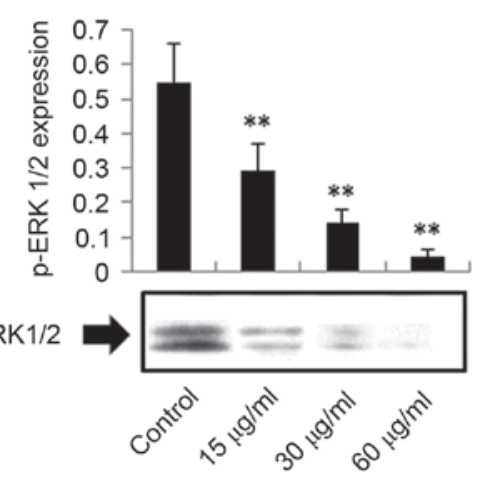

G

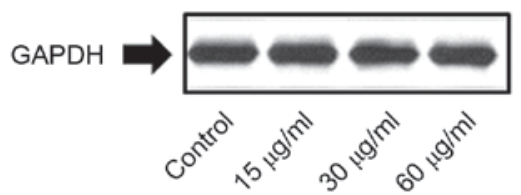

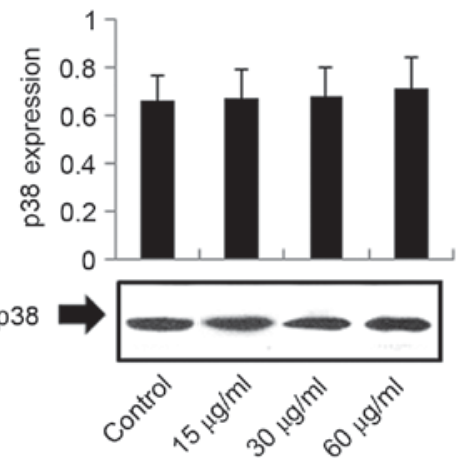

D

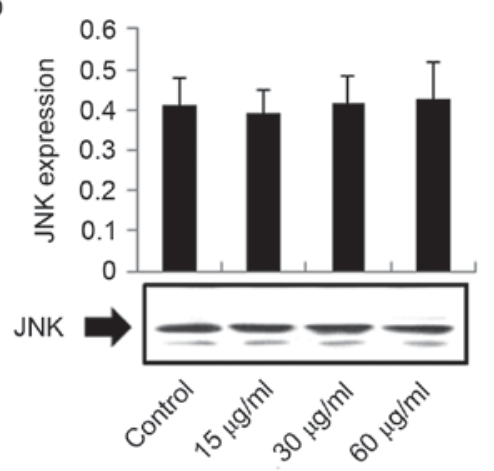

$\mathrm{F}$

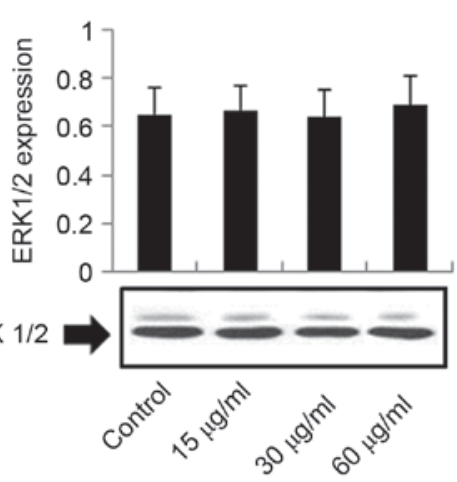

Figure 7. Effects of DMD on the protein expression levels of (A) p-p38, (B) p38, (C) p-JNK, (D) JNK, (E) p-ERK1/2,(F) ERK1/2 and (G) GAPDH. Total protein was extractedanddetectedby westernblotanalysisusing antibodiesagainstERK1/2,p-ERK1/2,JNK,p-JNK,p38andp-p38;GAPDHwasusedasaninternalcontrol.Dataare presented as the mean \pm standard deviation $(\mathrm{n}=4)$. ${ }^{* *} \mathrm{P}<0.01$ vs. the control group. DMD, 2-[(2E)-3,7-dimethyl-2,6-octadienyl]-6-methyl-2,5-cyclohexadiene-1,4-dione; ERK, extracellular signal-regulated kinase; JNK, c-Jun N-terminal kinase; p-, phosphorylated-. 
To investigate whether DMD-induced apoptosis of $\mathrm{H} 22$ cells was associated with the MAPK pathway, the present study detected the expression levels of JNK, ERK1/2 and p38 proteins, and the level of phosphorylation of these proteins. The results indicated that DMD significantly upregulated the expression levels of p-JNK and downregulated the expression levels of p-ERK1/2 dose-dependently, whereas DMD exhibited no obvious effect on JNK, ERK1/2, p38 and p-p38 protein expression, compared with control cells. These results indicated that DMD-mediated apoptosis may be associated with the MAPK pathway.

In conclusion, the results of the present study demonstrated that DMD isolated from APM exhibited a notable antitumor effect against $\mathrm{H} 22$ cells, and the potential underlying mechanism may be associated with mitochondria-mediated apoptosis via increased expression of cytochrome $c$, c-caspase-3, c-caspase-9, c-caspase-7 and Bax, and reduced expression of Bcl-2. In addition, the antitumor effects of DMD against $\mathrm{H} 22$ cells may also involve the MAPK pathway, as the results demonstrated increased $\mathrm{p}-\mathrm{JNK}$ expression and reduced p-ERK1/2 expression, which serve proapoptotic and cytoprotective roles, respectively.

\section{References}

1. Xie QC and Yang YP: Anti-proliferative of physcion 8-O- $\beta$-glucopyranoside isolated from Rumex japonicas Houtt. on A549 cell lines via inducing apoptosis and cell cycle arrest. BMC Complem Altern Med 14: 377, 2014.

2. Li JP, Zhao DL, Jiang HJ, Huang YH, Li DQ, Wan Y, Liu XD and Wang JE:. Assessment of tumor vascularization with functional computed tomography perfusion imaging in patients with cirrhotic liver disease. Hbpd Int 10: 43-49, 2011.

3. Bruix J and Llovet JM: Prognostic assessment and evaluation of the benefits of treatment. J Clin Gastroenterol 35 (5 Suppl 2): S138-S142, 2002.

4. Marra M, Sordelli IM, Lombardi A, Lamberti M, Tarantino L, Giudice A, Stiuso P, Abbruzzese A, Sperlongano R, Accardo M, et al: Molecular targets and oxidative stress biomarkers in hepatocellular carcinoma: An overview. J Transl Med 9: 171, 2011.

5. Katsuta E, Tanaka S, Mogushi K, Matsumura S, Ban D, Ochiai T, Irie T, Kudo A, Nakamura N, Tanaka H, et al: Age-related clinicopathologic and molecular features of patients receiving curative hepatectomy for hepatocellular carcinoma. Am J Surg 208: 450-456, 2014.

6. Kasai K, Kuroda H and Suzuki K: Adjuvant therapy after treatment of hepatocellular carcinoma. Nippon Shokakibyo Gakkai Zasshi 105: 787-794, 2008 (In Japanese).

7. Caraglia M, Giuberti G, Marra M, Addeo R, Montella L, Murolo M, Sperlongano P, Vincenzi B, Naviglio S, Prete SD, et al: Oxidative stress and ERK1/2 phosphorylation as predictors of outcome in hepatocellular carcinoma patients treated with sorafenib plus octreotide LAR. Cell Death Dis 2: e150, 2011.

8. Fokunang CN, Ndikum V, Tabi OY, Jiofack RB, Ngameni B, Guedje NM, Tembe-Fokunang EA, Tomkins P, Barkwan S, Kechia F, et al: Traditional medicine: Past, present and future research and development prospects and integration in the national health system of Cameroon. Afr J Tradit Complement Altern Med 8: 284-295, 2011.
9. Xie Q, Yang Y, Wang Z, Chen F, Zhang A and Liu C: Resveratrol-4-O-D-(2'-galloyl)-glucopyranoside isolated from Polygonum cuspidatum exhibits anti-hepatocellular carcinoma viability by inducing apoptosis via the JNK and ERK pathway. Molecules 19: 1592-1602, 2014.

10. Zhong YM and Feng YF: Advance on the chemical constituents and pharmacological effects of Atractylodes macrocephala Koidz. J Guangdong Coll Pharm: 218-221, 2012.

11. Peng W, Han T, Liu Q and Qin L: Chemical constituents from aerial part of Atractylodes macrocephala. Zhongguo Zhong Yao Za Zhi 36: 578-581, 2011 (In Chinese).

12. National Institute of Health (NIH): Public health service policy on humane care and use of laboratory animals. NIH, Bethesda, MD, USA 2002.

13. Resch M, Steigel A, Chen ZL and Bauer R: 5-Lipoxygenase and cyclooxygenase- 1 inhibitory active compounds from Atractylodes lancea. J Nat Prod 61: 347-350, 1998.

14. Yang XK, Xu MY, Xu GS, Zhang YL and Xu ZX: In vitro and in vivo antitumor activity of scutebarbatine $\mathrm{A}$ on human lung carcinoma A549 cell lines. Molecules 19: 8740-8751, 2014.

15. Mattern J and Volm M: Imbalance of cell proliferation and apoptosis during progression of lung carcinomas. Anticancer Res 24: 4243-4246, 2004.

16. Liu YL, Tang LH, Liang ZQ, You BG and Yang SL: Growth inhibitory and apoptosis inducing by effects of total flavonoids from Lysimachia clethroides Du by in human chronic myeloid leukemia K562 cells. J Ethnopharmacol 131: $1-9,2010$

17. Okada $\mathrm{H}$ and Mak TW: Pathways of apoptotic and non-apoptotic death in tumor cells. Nat Rev Cancer 4: 592-603, 2004.

18. Chipuk JE, McStay GP, Bharti A, Kuwana T, Clarke CJ, Siskind LJ, Obeid LM and Green DR: Sphingolipid metabolism cooperates with Bak and Bax to promote the mitochondrial pathway of apoptosis. Cell 148: 988-1000, 2012.

19. Delivani $P$ and Martin SJ: Mitochondrial membrane remodeling in apoptosis: An inside story. Cell Death Differ 13: 2007-2010, 2006.

20. Guerra-Castellano A, Díaz-Moreno I, Velázquez-Campoy A, De la Rosa MA and Díaz-Quintana A: Structural and functional characterization of phosphomimetic mutants of cytochrome c at threonine 28 and serine 47. Biochim Biophys Acta 1857: 387-395, 2016.

21. Zheng TS and Li X: Research progress in mitochondrial apoptosis pathway. Yixue Zongshu 19: 3282-3285, 2013 (In Chinese).

22. McIlwain DR, Berger T and Mak TW: Caspase functions in cell death and disease. Cold Spring Harb Perspect Biol 5: a008656, 2013.

23. Xu J, Jiang S, Li Y, Li M, Cheng Q, Zhao D, Yang B, Jia Z, Wang L and Song L: Caspase-3 serves as an intracellular immune receptor specific for lipopolysaccharide in oyster Crassostrea gigas. Dev Comp Immunol 61: 1-12, 2016

24. Gao N, Budhraja A, Cheng S, Yao H, Zhang Z and Shi X: Induction of apoptosis in human leukemia cells by grape seed extract occurs via activation of c-Jun NH2-terminal kinase. Clin Cancer Res 15: 140-149, 2009.

25. Chang L and Karin M: Mammalian MAP kinase signalling cascades. Nature 410: 37-40, 2001.

26. Pearson G, Robinson F, Beers Gibson T, Xu BE, Karandikar M, Berman K and Cobb MH: Mitogen-activated protein (MAP) kinase pathways: Regulation and physiological functions. Endocr Rev 22: 153-183, 2001.

27. Boutros T, Chevet E and Metrakos P: Mitogen-activated protein (MAP) Kinase/MAP kinase phosphatase regulation: Roles in cell growth, death, and cancer. Pharmacol Rev 60: 261-310, 2008.

28. Gao N, Budhraja A, Cheng S, Liu EH, Huang C, Chen J, Yang Z, Chen D, Zhang Z and Shi X: Interruption of the MEK/ERK signaling cascade promotes dihydroartemisinin-induced apoptosis in vitro and in vivo. Apoptosis 16: 511-523, 2011. 